\title{
Adverse Effects of Chemotherapy with Doxorubicin and Vincristine in Canine Transmissible Venereal Tumour
}

\author{
Anup Yadav ${ }^{1}$, Praveen Kumar ${ }^{2 *}$,okesh ${ }^{3}$, Ashwani Kumar ${ }^{2}$, Pankaj Kumar ${ }^{4}$, \\ Rajendra Yadav ${ }^{5}$, N.S. Bugalia ${ }^{1}$ and R.P. Diwakar ${ }^{6}$ \\ ${ }^{1}$ Department of Veterinary Gynaecology and Obstetrics, ${ }^{2}$ Department of Veterinary \\ Medicine, ${ }^{3}$ Department of Veterinary Surgery, (LUVAS, Hisar), India \\ ${ }^{4}$ Disease Investigation Laboratory, Rohtak (LUVAS, Hisar), India \\ ${ }^{5}$ RVDEC, Mahendergarh (LUVAS, Hisar), India \\ ${ }^{6}$ Department of Veterinary Microbiology, C.V.Sc\&A.H., N.D.U.A\&T., Kumarganj, \\ Faizabad (U.P), India \\ *Corresponding author
}

\section{A B S T R A C T}

\section{Keywords}

Transmissible Venereal Tumour (TVT), Doxorubicin and Vincristine

Article Info

Accepted:

17 November 2018

Available Online:

10 December 2018
Present study was conducted at TVCC, LUVAS, Hisar on Twenty-four dogs irrespective of age, breed, sex affected with canine transmissible venereal tumour (TVT). Affected dogs were divided equally into three groups on the basis of treatment with chemotherapeutic drugs viz. vincristine therapy (Group I) and doxorubicin therapy (Group II and III). Vomition, diarrhea, alopecia, allergic nodules and stomatitis were adverse effects of chemotherapy in TVT affected dogs. Maximum adverse effects of chemotherapy were recorded with vincristine therapy (Group I), followed by 14 days interval doxorubicin therapy (Group II)and minimum adverse effects with 21 days interval doxorubicin (Group III).

\section{Introduction}

Canine transmissible venereal tumour (TVT) is a benign reticulo endothelial tumour of the dog that mainly affects the external genitalia and this tumor contradicts the current view that cancer cells generate more mutations and inevitably become more aggressive if untreated. Naturally occurring TVT occurs in dogs, with no breed or sex predilection (Rogers et al., 1997; Murgia et al., 2006). TVT incidence has been reported in several areas around the world. However, it has mostly been found in tropical and subtropical urban areas with a large random mating population of free-roaming dogs with poor mating control (Das et al., 2000, Mello et al., 2005, Rogers et al., 1998). Tumor is spread by transplantation of tumor cells from the affected area to the mucous membrane, particularly to membranes that have lost their integrity. 
Sexual intercourse is major route of transmission of TVT. However, other social behaviors of dogs, such as licking and sniffing, are also able to promote the transmission of TVT (Papazoglou et al., 2001). Chemotherapy is the most effective and practical therapy, with vincristine sulfate being the most frequently used drug (Calvet et al., 1982). Vincristine, used as a chemotherapeutic agent, is a plant alkaloid and is widely used to treat various neoplastic disorders, such as, leukemias, lymphomas and sarcomas in dogs and cats (Dobson et al., 2008, Hahn, 1990]. This alkaloid disrupts cellular microtubule formation and exerts cytotoxic activity. This leads to inhibition of cell replication, including the replication of the cancer cells (Copocc, 2009). The TVT treatment by vincristine consist of weekly administration of at a dosage of 0.5 to 0.7 $\mathrm{mg} / \mathrm{m}^{2}$ of body surface area or $0.025 \mathrm{mg} / \mathrm{kg} \mathrm{b}$. wt. for a period of 4-8 weeks (Boscos et al., 2004]. There are various other chemotherapeutic agents like cyclophosphamide, vinblastine and methotrexate, which have been used alone or in combination in treatment regimen. However, there is no apparent advantage in the combination of chemotherapy over using vincristine alone (Richardson, 1981, Johnston, 1991., Brown et al., 1981; Yang et al., 1991).

Resistant cases of drugs viz. vincristine sulphate, vinblastine, cyclophosphamide, and methotrexate can be treated with doxorubicin (Richardson., 1981; Souza et al., 1998). Doxorubicin is the anthracycline and antitumour antibiotic family of medications. It works in part by interfering with the replication of DNA (Tacar et al., 2013). When total regression of the tumor cannot be achieved by chemotherapy, either electrocauterization or cryocauterization (Vermooten, 1987 and Rogers., 1997) or radiotherapy (Vermooten, 1987; McEvoy, 1987; Rogers, 1997 and Boscos and Ververidis, 2004) or surgical management
(Prier and Johnson, 1964; Jackson, 1969; Weir et al., 1987; Johnson,1994; Bradley, 1996; Rogers, 1997; Boscos and Ververidis, 2004) or immunotherapy (Amber et al., 1990 and Powers, 1968 and Rogers., 1997) or biotherapy (Richardson, 1981; Amber et al., 1990 and Johnston, 1991) are adopted.. In cases that fail to resolve with chemotherapy, radiotherapy has been reported to yield good results (Das et al., 2000).

Major advantages of chemotherapy are the high cure rate, ease of administration and potential usefulness in metastatic and multifocal disease. The disadvantages of chemotherapy are due to adverse effects observed during and after treatment e.g. loss of appetite, vomition, diarrhoea, neutropenia, alopecia, paresis etc. Behavioural changes are also observed during chemotherapy like animal feels lonely, occupies dark corner in the house and does not guard the house (Gadmade, 2006, Gandotra et al., 1993, Gandhimathi et al., 2011).

\section{Materials and Methods}

\section{Experimental animals}

Male and female dogs selected for the present study were client-owned clinical cases those were brought to the Teaching Veterinary Clinical Complex, LUVAS, Hisar for treatment purpose. Twenty-four dogs (male and female) affected with transmissible venereal tumour constituted into three experimental groups (8 animals in each group).

\section{Experimental design}

In present investigation, diagnosis of TVT and its therapeutic management was done. Diagnosis of TVT in dogs was made on the basis of clinical history given by owner followed by clinical examination and confirmed by histopathological examination 
of biopsy tissue. Variations in haematological and biochemical parameters in canine TVT were also recorded. Therapeutic efficacy of three different treatment regimens was evaluated and compared on the basis of regression of tumor as recorded by posttreatment clinical examinations conducted on days 7 to day 14 post-treatment (Group I), days 14 to day 28 post-treatment (Group II) and days 21 to day 42 post-treatment (Group III) or up to full regression of tumor.

\section{Experimental groups}

A total of twenty-four male and female dogs with the clinical history of bleeding from penis, prepuce and cauliflower like growth on base of penis in males and vaginal bleeding and cauliflower like growth in vagina in females following mating were divided equally into three groups each comprising of eight dogs irrespective of sex.

Group I (n=8): Male and female dogs were treated with Vincristine sulphate @ $0.025 \mathrm{mg} /$ $\mathrm{kg}$ b. wt., IV at weekly interval. The vincristine was administered on Day 0, Day 7 and Day 14

Group II (n=8): Male and female dogs were treated with Doxorubicin Hydrochloride @ $30 \mathrm{mg} / \mathrm{m}^{2}$ [Surface area $=$ Body weight ${ }^{0.67} \mathrm{X}$ $\mathrm{K} / 10^{4}$ - Sandhu and Rampal (2006)] IV in $100 \mathrm{ml}$ NSS. The Doxorubicin was administered on Day 0, Day 14 and Day 28

Group III (n=8): Male and female dogs were treated with Doxorubicin Hydrochloride @ $30 \mathrm{mg} / \mathrm{m}^{2} \quad$ IV in $100 \mathrm{ml}$ NSS. The Doxorubicin was administered on Day 0, Day 21 and Day 42.

\section{Diagnosis}

Dogs (both male and female) suspected for the TVT were diagnosed on the basis of clinical history recorded from owners and confirmed by histopathological examination of biopsy tissue of tumour mass. In addition haematological and biochemical parameters were monitored.

\section{Procedure for clinical examination and adverse effect of drugs}

TVT's were examined per vaginum in female dogs and by backward retraction of prepuce in male dogs and confirmed by the presence of cauliflower like tumour mass on the base of penis and vagina. The tumors were examined for shape, size, location and presence of bleeding associated with them. Adverse effects like vomition, diarrhoea, alopecia, stomatitis, allergic nodules of chemotherapy treated dogs affected with TVT were also recorded in affected dogs.

\section{Results and Discussion}

\section{Adverse effects of chemotherapy in canine TVT}

Adverse effects of cytotoxic drugs recorded in TVT affected male and female dogs (Group I, Group II and Group III) (Table 1).

\section{Vomition and diarrhoea}

Vomition and diarrhoea were observed in 5 out of 8 dogs and 4 out of 8 dogs respectively in vincristine regimen (Group I). Similar adverse effect with vincristine was recorded by Amber et al., (1990); Gandotraet al., (1993) and Gandhimathi et al., (2011).

Vomition and diarrhoea were observed in 4 out of 8 dogs and 2 out of 8 dogs respectively in doxorubicin regimen (Group II) and 2 out of $8 \mathrm{dogs}$ showed both adverse effects in doxorubicin regimen (Group III). Similar adverse effect with doxorubicin was recorded by Talker, (2001); Gadmade, (2006) and Gandhimathi et al., (2011). 
Vomition after cytotoxic drug administration is consequential to drug induced damage of gastro-intestinal epithelium, liver, kidney and brain (Dobson and Gorman, 1993) and can be minimized following fluid therapy and antiemetics (Gandotra et al., 1993).

Morrison (1998) reported that the nonspecific epithelial cells damage of the intestine results in malabsorption resulting in diarrhoea, whereas Dobson and Gorman (1993) reported that the direct cytotoxic action of the drug on the rapidly dividing cells of the oral basal epithelial, gastric mucosa and intestinal crypt epithelium might result in gastrointestinal toxicity. It may also occur as a result of non-specific immunosuppression . Rehydration therapy along with antimicrobial therapy and supportive therapy was instituted that helped in speedy recovery in most of the affected cases.

\section{Alopecia}

Alopecia was recorded in 2 out of 8 dogs after vincristine therapy (Group I). Similarly, alopecia was recorded after vincristine chemotherapy in canine TVT (Amber et al., 1990, Gandotra et al., 1993 and Gandhimathi et al., 2011).

Only one out of 8 dogs showed alopecia after doxorubicin treatment regimen (Group II). None of the dogs showed alopecia following doxorubicin treatment regimen (Group III). Alopecia increased during course of chemotherapy and dog recovered from alopecia after 4-5 week after chemotherapy. Morrison (1998) also reported that alopecia was not observed after Doxorubicin chemotherapy and present observation are in concurrence with this report.

Dobson and Gorman (1993) reported silky or curly coat breeds to be affected with alopecia. Recorded alopecia in TVT dogs with chemotherapy could be due to cutaneous toxicity.

\section{Stomatitis}

Stomatitis was observed in one dog in each group (vincristine- Group I and doxorubicinGroup III) and could be attributed to individual sensitivity of dog to chemotherapy.

\section{Allergic nodules}

Allergic nodules were recorded in 2 out of 8 dogs in vincristine treatment regimen (Group I), 4 out of 8 dogs in doxorubicin treatment regimen (Group II) and 3 out of 8 dogs (37 $\%$ ) in doxorubicin treatment regimen (Group III).

Allergic nodules observed during course of chemotherapy subsided following avil therapy for three consecutive days (Fig. 1).

Table.1 Adverse effects of chemotherapy in canine TVT

\begin{tabular}{|l|c|c|c|}
\hline Clinical Signs & $\begin{array}{c}\text { GROUP I } \\
(\mathrm{n}=8)\end{array}$ & $\begin{array}{c}\text { GROUP II } \\
(\mathrm{n}=8)\end{array}$ & $\begin{array}{c}\text { GROUP III } \\
(\mathrm{n}=8)\end{array}$ \\
\hline Vomiting & 5 & 4 & 2 \\
\hline Diarrohea & 4 & 2 & 2 \\
\hline Alopecia & 2 & 1 & - \\
\hline Stomatitis & 1 & - & 1 \\
\hline Allergic Nodules & 2 & 4 & 3 \\
\hline
\end{tabular}


Fig.1 Histogram showing adverse effects of cytotoxic drugs in TVT affected male and female dogs (Group I, Group II and Group III)

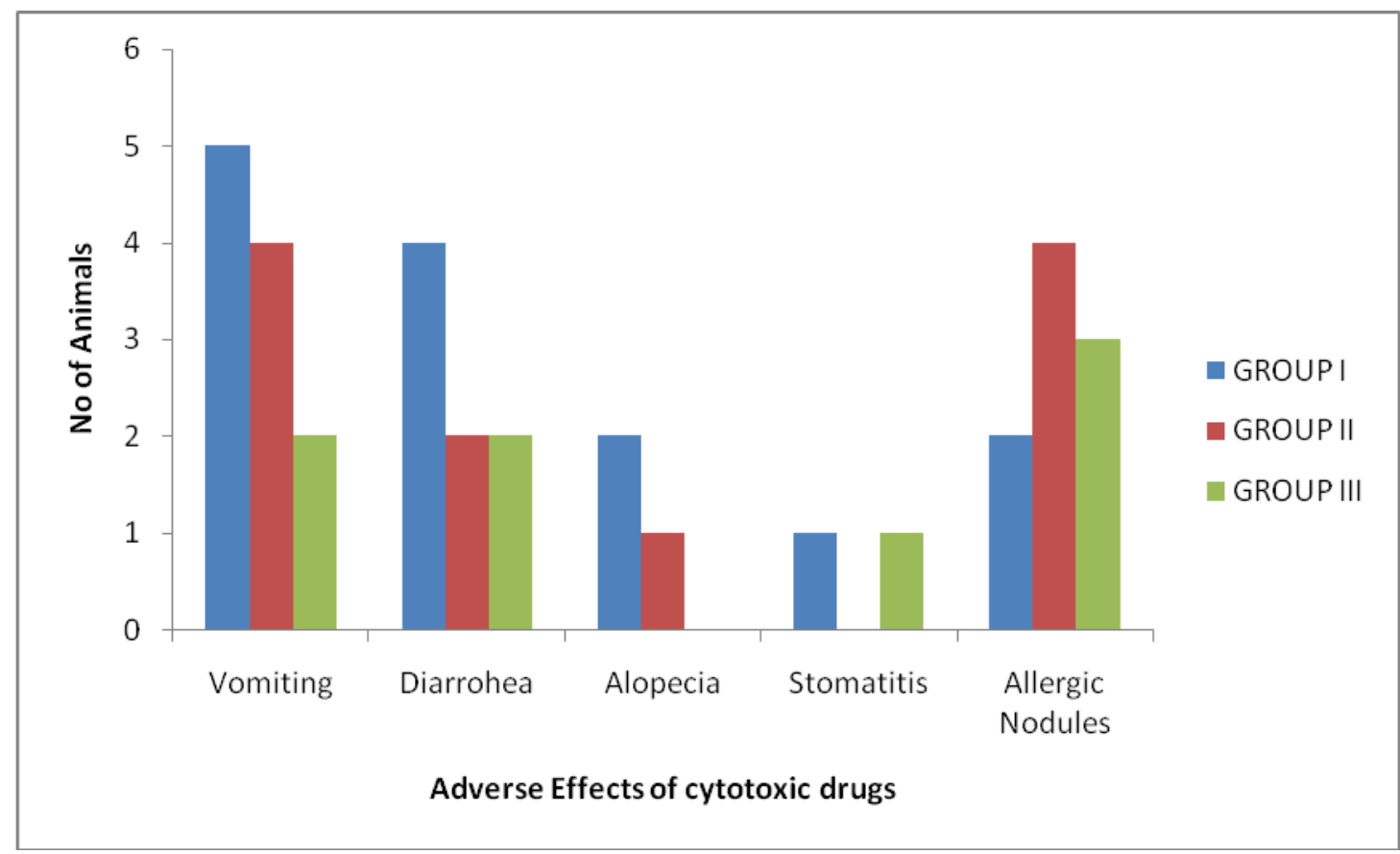

It is concluded as vomiting and Diarrhoea were most common and alopecia and allergic nodules were less common adverse effects with vincristine chemotherapy (Group I). Vomiting and allergic nodules were most common and diarrhea and alopecia were less common with doxorubicin chemotherapy (Group II). Allergic nodules were most common and vomiting, diarrhea and stomatitis were less common adverse effects with doxorubicin chemotherapy (Group III). Maximum adverse effects of chemotherapy were recorded with vincristine therapy (Group I), followed by 14 days interval doxorubicin therapy (Group II) and minimum adverse effects with 21 days interval doxorubicin therapy (Group III).

\section{References}

Amber, E. I., Henderson, R.A., Adeyanju J.B. (1990). Single-drug chemotherapy of canine transmissible venereal tumor with cyclophosphamide, methotrexate, or vincristine. $J$ Vet Intern Med: 4(3):144-147.

Boscos C. M., Ververidis H. N. 2004. Canine TVT-clinical findings, diagnosis and treatment. In proceedings of the 29th World Small Animal Veterinary Association, Oct 6-9. Rhodes, Greece.

Bradley, R.L. (1996). Tumoresvulvovaginais. In: Borjab, MJ, ed. Técnicasatuaisemcirurgia de pequenosanimais. 3ed. São Paulo: Ed Roca; 385-387.

Brown N.O., MacEwen E.G., Calvert C.A. (1981). Transmissible venereal tumor in the dog. California Vet; 3:6-10.

Calvert, C.A., Leifer, C.E. and MacEwen, E.G. (1982).Vincristine for treatment of transmissible venereal tumours in the dog. J. of the Am.Vet.Med. Assoc., 181: 163-164

Coppoc G. L. 2009. Chemotherapy of neoplastic diseases. pp. 1205-1231. In: Veterinary Pharmacology and Therapeutics. 9th ed. (Riviere J. E. and 
Papich. M. G. eds.), Willey-Blackwell, Ames.

Das U., Das A. K. 2000. Review of canine transmissible venereal sarcoma. Vet. Res. Commun. 24: 545-556.

Dobson, J. M., and Gorman, N.T. (1993), Cancer chemotherapy in small animal practice. Blackwell scientific publication London: 67-154.

Dobson J. M., Hohenhaus A. E., Peaston A. E. 2008. Cancer chemotherapy. pp. 330-366. In: Small Animal Clinical Pharmacology 2nd ed. (Maddison, J. E., Page, S. W. and Church, D. B. eds.), Saunders Elsevier, Edinburgh.

Gadmade.(2006). Studies on unusual vaginal tumours in bitches with special Reference in bitches with special reference to therapeutic measures. M.V.Sc.thesis work submitted to Maharashtra Animal \& Fishery.

Gandhimathi, D., Gurupriya, G., Arivuselvan, P., Sridevi and Joseph, Ciclia (2011). Effect of doxorubicin therapy on transmissible venereal tumour in dogs. Ind. J. of Animal reproduction 32(2): 71-73

Gandotra, V.K., Chauhan, F.S., and Sharma, R.D. (1993).Occurrence of canine transmissible venereal tumour and evaluation of two treatments. Indian Veterinary Journal, 70: 854-857.

Hahn K. A. 1990. Vincristine sulfate as single-agent chemotherapy in a dog and a cat with malignant neoplasms. J. Am. Vet. Med. Assoc. 197: 504-506.

Jackson O.F. (1969). Transmissible Venereal tumour in dogs Vet. Rec.84:125.

Johnson, C.A. (1994). Infecçõesgenitais e tumor venéreotransmissível. In: Nelson RW, Couto CG, eds. Fundamentos de MedicinaInterna de Pequenos Animais. Rio de Janeiro: Guanabara Koogan; 525.

Johnston S.D. (1991). Performing a complete canine semen evaluation in a small animal hospital. Vet Clin North Am Small AnPract; 21(3):545-551.

McEvoy, G.K. (1987). American Hospital Formulary Service Drug information. In: Bethesda, MD. American Society of Hospital and Pharmacists.

Mello, Martins M. I., Ferreira de Souza F., Gobello C. 2005. The canine transmissible venereal tumor: etiology, pathology, diagnosis and treatment. In: Recent Advances in Small Animal Reproduction. (Concannon, P. W., England, G., Veretgegen, J. and LindeForsberg, C. eds.), International Veterinary Information Service, Ithaca NY (www.ivis.org) Apr 25, 2005: A1233.0405.

Morrison, W.B. (1998). Cancer management in dogs and cats: medical and surgical management, 1st edn. A Wolter Klover company, Philadephia PP. 583- 584.

Murgia, C., Pritchard, J.K., Kim, S.Y., Fassati, A. and Weiss, R.A. (2006).Clonal origin and evolution of a transmissible cancer. Cell, 126: 477487.

Papazoglou L. G., Koutinas A. F., Plevraki A. G., Tontis D. 2001. Primary intranasal transmissible venereal tumour in the dog: a retrospective study of six spontaneous cases. J. Vet. Med.A Physiol. Pathol. Clin. Med. 48: 391400.

Powers, R.D. (1968). Immunologic properties of canine transmissible Venereal sarcoma. Am. J Vet Res29(1): 637 to 1645.

Prier, J.E. and J.H. Johnson (1964). Malignancy in a Canine Tranbsmissible Venereal tumour. $J$ of the Am Vet MedAssoc., 145: 1092-1094.

Richardson, R.C. (1981). Canine transmissible venereal tumour. Comp Contin Educ Pract Vet; 3:951-956.

Rogers KS, TVT. Compend Continum Education Practice Veterinaria. 1997; 
19:1036-1042.

Rogers K. S., Walker M. A., Dillon H. B. 1998. Transmissible venereal tumor: a retrospective study of 29 cases. J. Am. Anim. Hosp. Assoc. 34: 463-470.

Sandhu, H.S., Rampal, S., (2006). Essentials of Veterinary Pharmacology and Therapeutics First Edition pp: 13591381.

Souza, F.F., de, Tinucci-Costa, M., FariaJr, $\mathrm{D}(1998)$. Doxorubicin treatment for recurrent canine transmissible veneral tumor. In: Proceedings of the XXIII Congress of the World Small Anim Vet Assoc., Pp. 772.

Tacar, O; Sriamornsak, P; Dass, CR (February 2013). "Doxorubicin: an update on anticancer molecular action, toxicity and novel drug delivery systems". The Journal of Pharmacy and
Pharmacology. 65 (2): 157-70.

Talekar, S.H. (2001). Comparative study of surgical excision and chemotherapeutic agents in the treatment of mammary tumours in canine. Unpublished M.V.Sc, thesis submitted to the $\mathrm{Dr}$ Punjabrao Deshmukh Krishi Vidyapeeth, Akola.

Weir, E.C., Pond, M.J., Duncan, J.R. (1987).Extragenital located TVT tumor in the dog. Literature review and case reports.J Am AnimHospAssoc, 14: 532536.

Yang, T.J., Palker, T.J., Harding, M.W. (1991). Tumor size, leukocyte adherence inhibition and serum levels of tumor antigen in dogs with the canine transmissible venereal sarcoma. Cancer Immunol. Immunoth, 33:255-256.

\section{How to cite this article:}

Anup Yadav, Praveen Kumar, Lokesh, Ashwani Kumar, Pankaj Kumar, Rajendra Yadav, N.S. Bugalia and Diwakar, R.P. 2018. Adverse Effects of Chemotherapy with Doxorubicin and Vincristine in Canine Transmissible Venereal Tumour. Int.J.Curr.Microbiol.App.Sci. 7(12): 2488-2494. doi: https://doi.org/10.20546/ijcmas.2018.712.283 